\title{
Positive and negative implications entailed by fixed-term employment contracts
}

\author{
Mihaela-Emilia Marica ${ }^{\mathrm{a}, 1}$ \\ ${ }^{a}$ The Bucharest University of Economic Studies, Romania
}

\begin{abstract}
Generally, fixed-term employment contracts are seen as a stepping stone to permanent employment; they have become popular among the flexible forms of work contracts, and are the object of an increasing number of debates and assessments, investigating both the respective legislation and the specific consequences on the parties concluding a fixed-term employment contract. Despite the positive aspects of temporary employment - a positive effect on the rate of employment, and the common perception of such contracts as a preliminary step to permanent employment, as well as the flexibility they bring to the labor market one cannot ignore the negative implications of fixed-term contracts on the nature of the employment relationship, the system of social protection, the working conditions, the economic security, and the job stability.

Based on these considerations, the present paper investigates the advantages and disadvantages of the individual fixed-term employment contract from the standpoints of both employers and employees. Obviously, this approach aims to explore the usefulness and importance of these contract types, as means for balancing the needs of employers and employees on the labor market, and for identifying concrete instances that justify the liberalization of fixed-term employment, despite all the inherent risks entailed by any type of non-standard work: lack of job security; reduced social protection and security for those concluding such a contract.
\end{abstract}

Keywords: fixed-term contract; flexible employment; atypical work

\section{JEL codes: K31}

\footnotetext{
${ }^{1}$ Corresponding author: Department of Law, The Bucharest University of Economic Studies, Bucharest; Piața Romană, nr. 6, Sector 1, Bucharest, tel. (+40) 726.00.70.69; email address: avocatmihaelamarica@yahoo.com
} 


\section{Introduction}

Fixed-term (temporary) employment contracts are among the most common ${ }^{1}$ forms of employment that depart from the standard type. In many member states of the European Union (EU), this type of employment has become a key characteristic of the labor market. In 2014, more than $15 \%$ of the employed individuals across Europe had temporary work contracts. The proportion, however, can reach much higher levels - for instance, $28.4 \%$ in the case of Poland, which has the greatest number of fixed-term employment contracts in Europe ${ }^{2}$.

Generally, fixed-term employment contracts are seen as a stepping stone to permanent employment (Babos, 2014) ${ }^{3}$; they have become popular among the flexible forms of work contracts, and are the object of an increasing number of debates and assessments, investigating both the respective legislation and the specific consequences on the parties concluding a fixed-term employment contract. Despite the positive aspects of temporary employment - a positive effect on the rate of employment, and the common perception of such contracts as a preliminary step to permanent employment (Burgoon \& Dekker, 2010), as well as the flexibility they bring to the labor market - one cannot ignore the negative implications of fixed-term contracts on the nature of the employment relationship, the system of social protection, the working conditions, the economic security, and the job stability. The workers having concluded such atypical contracts, are considered „vulnerable workforce” from the standpoint of labor law, because of poor jobs offering low payment and scarce benefits, limited social protection, low training and skills, and lack of opportunities for promotion. Also, the insufficient stability of jobs and income, the insecurity concerning the future prospects for the workers on this type of employment contract - most of the times, entrapped in temporary jobs undertaken repeatedly or even leading to unemployment, rather than resulting in permanent employment on a steady position (Babos, 2014) - are aspects that increase the vulnerability of temporary employees with fixed-term contracts.

Based on these considerations, the present paper investigates the advantages and disadvantages of the individual fixed-term employment contract from the standpoints of both employers and employees. Obviously, this approach aims to explore the usefulness and importance of these contract types, as means for balancing the needs of employers and employees on the labor market, and for identifying concrete instances that justify the liberalization of fixed-term employment, despite all the inherent risks entailed by any type of non-standard work: lack of job security; reduced social protection and security for those concluding such a contract. 


\section{Benefits from the employers' standpoint}

Beside the increased flexibility ensured by this specific type of work relationship, the individual fixed-term (temporary) employment contract is very important for the strategy chosen by employer companies in order to cut down on their expenses. For instance, by employing temporary workers, businesses attempt to avoid the uncertainties caused by too high economic risks, adapting their own particular economic situation to the unpredictable fluctuations of the marketplace or market trends. Research into the benefits of this type of employment reveals lower costs for dismissal, compared to the dismissal of employees with steady jobs and permanent employment contracts. The more flexible regulations and lower costs involved by the termination of fixed-term contracts push employers to seek this alternative, which is much cheaper and more attractive than regular employment contracts.

Actually, the rigid regulations concerning permanent employment - which normally require employers to comply with strict and expensive stipulations that regulate the dismissal of employees, or even oblige them to offer severance pay if the job is suppressed (Dimitriu, 2016), are one of the major reasons why employers turn to temporary workers. In their case, the fixed-term employment contract simply expires at the end of the period it covers, without obliging the employer to any legal procedure or obligation. Another advantage for employers, and possibly the most important one, is the fact that fixed-term contracts also involve lower social security costs, such as the contributions to pension funds (retirement funds) or health insurance.

Specialized labor law literature (Vettori, 2008) has noted that all these advantages enjoyed by employers are actually as many disadvantages to their employees. For instance, the fact that an individual fixed-term contract is terminated at the end of the period it covers, actually points to an important issue: the low security and stability of that job for the respective category of employees who sign such a contract. Also, cutting the costs related to the social security system - an advantage from the employer's standpoint - becomes a disadvantage for the temporary employee, who is deprived of this package of social benefits (health insurance and pension). This certainly aggravates the economic and social instability faced by fixed-term employees, and may entail a number of negative consequences - not only regarding their income and social security, but also regarding their families, as it affects their decisions on starting a family or the number of children they might have (Alvarado, 2014) ${ }^{4}$. However, more can be said about the possible benefits brought to the employer by this flexible type of work. This type of employment contract can be used in order to bypass the complexity of some staff recruitment processes, and especially to test new types of business, for which it is hard to predict the necessary number of employees. Thus employers find it much more 
convenient to start by hiring people with individual fixed-term employment contracts, and later transfer them - if necessary - to steady positions by concluding permanent individual employment contracts (Alvarado, 2014), also benefitting from the experience these workers have gained in that line of work. Consequently, this atypical form of employment is convenient not only because employers obtain reduced costs and become more competitive, but also because it provides them with an opportunity to evaluate the professional qualities of their employees, before engaging in a standard relationship (Elke et al., 2012). A fixed-term employment contract can be used as an extended probation period, which offers increased safety and benefits for the employers as it enables them to appraise the performance of an employee so that permanent contracts can be offered only to skilled and tested workers (Mooi-Reci \& Dekker, 2015) ${ }^{5}$. This is an additional positive aspect of fixed-term employment contracts, from the standpoint of the employers.

Like other atypical work arrangements, the proliferation of fixed-term employment - a working tool that increases the flexibility of labor market - is also motivated by the general perception of this type of contract, as a means to reduce unemployment thus having a positive influence on the level of employment (Ludera-Ruszel, 2016) ${ }^{6}$. Specialized literature (Alvarado, 2014) has pointed out that by resorting to individual fixed-term contracts, the labor market „can increase the turnover of the workforce, shifting from unemployment to employment and vice-versa, and it can also influence the probability of leaving unemployment" (Alvarado, 2014) ${ }^{7}$. The increase in the number of fixed-term contracts, is seen as directly proportional to the increase in the general level of employment during the expansion stage of the business cycle (economic cycle), a level that may become lower during the recession stage of the business (economic) cycle.

We also note that this assumption is rather theoretical, and it is not yet certain - not an established fact, at least so far - that the proliferation of fixed-term employment contracts actually triggers an increase in the employment level, finally resulting in a lower level of unemployment. Literature provides evidence of this (Dimitriu, 2016). For example, the legislation of Poland, which until recently allowed fixedterm contracts to be concluded freely, had a particular regulatory mechanism. The (excessive) liberalization of this type of contract on the Polish labor market, by dropping any restrictive regulations - such regulations could be implemented at will by the parties, which did not have to motivate their options - has generated the greatest number of fixed-term employment contracts in Europe (for instance in $2014,28 \%$ of the employment contracts were fixed-term). This, however, did not lead to lower levels of unemployment than the European average. We may also mention the cases of Spain and Portugal, where one out of five employees has concluded such a contract, but the level of unemployment has not changed significantly. Can we, then, justify the use of fixed-term contracts in the fight against unemployment, when the surveys produce pessimistic results? Especially since, as we shall see, this specific type of employment contract entails many 
negative effects for the workers, effects which ought to be compensated - at least partially - by this expected increase in the level of employment.

\section{Benefits from the standpoint of employees}

Work on fixed-term contracts is often regarded by employees as inferior to work carried out on a standard employment contract. However, according to the European views, this contractual form significantly boosts the chances of workers to obtain permanent employment ${ }^{8}$ or find a job that suits their needs. In other words, due to various life circumstances, certain categories of workers are unable or unwilling to work on a permanent basis, and thus the fixed-term contract is the favored choice for joining the labor market. This category includes, for instance, young students who want to earn some money, but are available only during holidays, as well as persons in the rural areas, who seek employment only in winter?.

For other groups of workers, the fixed-term contract marks the so-called „stepping stone" or the transition to permanent employment (Babos, 2014), as well as an opportunity to gain experience and benefits concerning the training and professional development, if they are inexperienced in that type of work (Blanpain et al., 2010) ${ }^{10}$. However, there are categories of persons who are greatly affected by this type of employment: mainly young people (aged between 15 and 29), women, as well as persons without higher education and less skilled professionally.

A survey conducted on this subject has revealed that the probability to hold a fixedterm contract is inversely proportional to the level of education, that is, the highly educated employees are less likely to have a fixed-term employment contract than the less educated, less skilled persons. The latter have a 3.2\% lower chance for permanent employment (Alvarado, 2014). In other words, for these categories of workers, fixed-term contractual arrangements are not normally a voluntary choice, but rather an alternative to unemployment (Ludera-Ruszel, 2016). For this reason, we think that for the labor market, this specific type of employment is useful only up to a certain point, that is, the moment when the option of a worker signing such a fixed-term employment contract is no longer a free choice, but is the result of some constraints (for example, the lack of opportunities for permanent employment), and on the other hand, the undesirable situation where temporary jobs, obtained by fixed-term individual employment contracts, fail to lead to permanent employment (Babos, 2014) $)^{11}$, but rather tend to lead to more temporary jobs or unemployment, at the end of the duration covered by the contract $(\text { Alvarado, 2014) })^{12}$. As we shall demonstrate below, beyond this point the fixedterm workers have increasingly vulnerable positions, entailed by the temporary character of the employment contract; this vulnerability is increased by the succession of temporary jobs, because of the lack of other options. 
Fixed-term contracts offer higher job satisfaction and ensure the work-life balance only for certain categories of workers, for whom this type of employment is justified; however, for the vast majority of workers, this non-standard contractual arrangement is merely an alternative for unemployment or a way of joining the labor market, which is not based on a voluntary option of the respective persons. Many investigations have been conducted to reveal the employees' level of satisfaction with this type of contract. They found that indeed, job satisfaction is significantly lower among the fixed-term workers. Interestingly, the key element influencing the satisfaction level is not necessarily the type of contract, but rather, the perception of job security it entails (Elke et al., 2012). This means that a generous social welfare system, providing high unemployment benefits (also called unemployment insurance, or unemployment compensation) can increase the job satisfaction of fixed-term workers, which may thus match the satisfaction level of permanent employees with steady jobs, thus leading to a win-win situation for all parties involved in the employment contract.

\section{Disadvantages from the employees' standpoint}

The increased flexibility of labor market, brought by fixed-term employment contracts, also has negative effects. They are manifest especially in the many vulnerabilities challenging this category of workers (actually, all workers engaged in non-standard employment). The temporary character of the fixed-term contracts renders these workers vulnerable, and places them on a special, disadvantageous position compared to standard workers. We shall dwell on the special vulnerabilities later, considering all elements which define this specific type of employment: the economic, social, social welfare factors as well as the professional development and training of those who sign such a contract. For now, it is important to understand that despite the credit given to fixed-term contracts as an attractive alternative to unemployment, there is this significant disadvantage: they increase the insecurity of fixed-term labor, which is precisely one of the causes of vulnerabilities.

Specialized literature provides many investigations into the negative consequences entailed by fixed-term employment: disparities in income, working and employment conditions, social welfare rights between the fixed-term employees and those holding a standard employment contract, respectively. These surveys have revealed that the labor market is divided, between the workers with permanent, steady jobs (the so-called insiders) and those with a fixed-term employment contract (the outsiders). According to this insider/outsider pattern, the former have stable, well-paid employment and a high level of social protection and security, while the fixed-term workers hold a significant part of secondary economy, which provides unstable, unprotected jobs with low social rights and benefits; moreover, they can be easily dismissed in the event of economic crises 
(Mooi-Reci \& Dekker, 2015). It has been found that these circumstances defining the "outsiders", sphere entail higher risks of unemployment in the future for these workers. Indeed, on the one hand the jobs taken by fixed-term workers are less skilled and easier to find, thus generating shorter unemployment periods; but on the other hand, these jobs are also more easily lost and consequently increase the risk of unemployment for the future (Mooi-Reci \& Dekker, 2015).

This is why the fixed-term employment contracts are associated with great potential precarity, expressed as follows:

\section{a) Regarding the job instability and the protection granted to the employees on a fixed-term employment contract.}

The job instability entailed by this type of employment, caused by the uncertainty concerning the future of a worker on fixed-term contract ${ }^{13}$, is probably the greatest of all vulnerabilities. The legislation regulating fixed-term employment contracts does not provide the same level of job security as traditional employment does. These significant disparities in the legislative provisions governing the protection offered to permanent employment versus fixed-term employment contracts, is mainly reflected by the perceived dimension of the risk of dismissal for the two categories of employees. Juridical literature has pointed out that the standard model (permanent employment) continues to guarantee greater protection and job security, because the perceived risk of job loss and consequently unemployment is lower among the employees on a permanent employment contract, compared with their counterparts on non-standard contracts (Ludera-Ruszel, 2016).

In this context, we mention that there are legal systems that are acknowledged for their efforts undertaken in order to diminish the precarity level characteristic to this specific category of workers, by strengthening the specific protection granted to those who sign such contracts. This is achieved by imposing strict rules that regulate the dismissal of the employees on fixed-term contracts - usually, not before the contract has expired. The most edifying examples are provided by the legal provisions in Finland, Germany, Italy, which aim to increase as much as possible the specific protection for fixed-term employees, in order to reduce the risk of abuse in this type of employment. For instance, in Finland, a fixed-term employee can be dismissed only for disciplinary reasons. It is also forbidden to suppress a job for reasons independent from the person of the employee; if the employee is dismissed, however, the employer has to pay them the due salary until the contract expires (Dimitriu, 2016). In the same spirit the legislation of Germany dictates that a fixed-term employment contract cannot normally be terminated before its term has expired, or the project that makes the object of the contract has been completed, unless a clause has been inserted in the employment contract to this effect (Kothe \& Rosendahl, 2013). 
Moreover, the fact that the provisions of the „Protection Against Unfair Dismissal Act" (germ. Kündigungsschutzgesetz) - including the circumstances of contract termination - equally apply to permanent employees and temporary employees, is in fact a guarantee for the job protection offered to the workers on fixed-term contracts (Ludera-Ruszel, 2016) ${ }^{14}$. In the same context, a pleasant surprise is provided by the legal system of the Netherlands, where The Flexibility and Security Act of 1999 aimed to increase the flexibility of labor market in the benefit of employers, by relaxing the conditions for hiring and dismissing, but also strengthening employees' protection through equal protection rights granted to permanent workers, on the one hand, and fixed-term workers, on the other. Similarly, an advantageous solution was offered to the employees on a fixed-term contract, by stipulating that the fixed-term contract will automatically become a permanent employment contract, if maximum three consecutive fixed-term contracts (without interruptions longer than 3 months between them) have been concluded, and the successive fixed-term contracts have covered maximum 3 years (Mooi-Reci \& Dekker, 2015).

A different perspective on legal regulations can be found, for instance, in Poland, where the fixed-term employment contract can be terminated at any time through a notice given by the employer, without any obligation incumbent on the latter to justify this option, as is the case for a permanent employment contract. There are a few exceptions to this rule, concerning the contracts concluded with those categories of employees who are protected by law against dismissal (those on maternity/paternity leave, those on childcare leave, as well as those employees with less than 4 years to go until they reach the age of retirement). Another factor that widens the gap between the job security level, for the two types of employment contracts - fixed-term and standard, respectively - concerns the employer's obligation to consult the union to which the employee is affiliated, announcing his intention to notify the employee of the termination of the contract, an obligation that applies only for permanent employment contracts. This means that the workers on a fixed-term contract cannot protest against the wrongful termination of his contract for lack of well-founded reasons (as a standard employee could), but only for illegal termination or unacceptable termination ex lege (Ludera-Ruszel, 2016).

Although as we have seen, in countries such as Finland, Germany, Italy, job protection has known a particular evolution, based on the individual fixed-term employment contract, however job security is still not similar for temporary workers and standard, permanent workers, respectively. The situation is even more worrisome in Poland, where there is a great disproportion between the protection of fixed-term employment and permanent employment, in the favor of the latter. We may even assert that this protection is virtually missing in the case of fixed-term employees, under this legal system. 


\section{b) Regarding the inequality of training and promotion opportunities}

The employee's vulnerabilities, generated by this type of employment, also have consequences on the hiring and working conditions. In the context of our analysis, we mention the empirical data recorded by specialized literature (Mooi-Reci \& Dekker, 2015; Cutuli \& Guetto, 2013), revealing a major discrepancy between the employers' investments in the professional development and training of temporary workers versus permanent workers. This fact is seen as strongly influenced by the cost-benefit ratio from the standpoint of the employer. More precisely, if the period while the employer will derive profit from such investments into the professional development of fixed-term workers is short, then the interest of employers in providing training for the development of this workforce segment is low (Cutuli \& Guetto, 2013). This explains employers' preference for the professional development and training of permanent workers, perceived as "their own" (Dimitriu, 2016), versus their significantly lower interest in temporary workers (Elke et al., 2012) ${ }^{15}$, generally hired in order to satisfy some temporary need for labor force.

We note that this low interest from the part of employers in the opportunities for professional development and training of this category of employees, has negative influence on their chances to gain the technical skills and knowledge required in the respective companies; fixed-term workers will be less skilled than standard ones. On the other hand, the drawback caused by the unequal distribution of training opportunities between the two categories of employees, creates a major competitive disadvantage for the fixed-term workers, with negative implications on the chances for professional development and promotion. Under such circumstances, a fixed-term worker's opportunities to have his/her contract renewed are diminished and, consequently, the risk of future unemployment increases (Mooi-Reci \& Dekker, 2015) ${ }^{16}$.

The inequality in the opportunities for professional development and training offered to temporary workers, also has economic implications: there is a tendency to ascribe this discrepancy to the unfavorable financial circumstances. In other words, if the financial resources of a business, intended for the employees' professional development and training, are limited, then it is very likely that the temporary workers (known as outsiders) will be affected by cuts. For this reason, indeed, the more frequently fixed-term contracts are used - as a favored means for cutting production expenses and dealing with temporary needs of employers, and not so much as a means for assessing the productivity of a possible permanent worker -, the more acutely will fixed-term workers feel this discrepancy in the opportunities for professional development and training, during times of economic crisis (Cutuli \& Guetto, 2013). 
An example confirming this hypothesis is Spain, where the disadvantageous economic circumstances of 2008 seemed to aggravate this problem, resulting in a segmentation of labor market and the proliferation of temporary employment contracts to the detriment of the permanent employment ones. There are several reasons in the particular case of this legal system. Firstly, the legislation concerning the fixed-term employment contracts strongly influenced the vulnerable position of temporary workers on the labor market, leading to contractual segregation between temporary and permanent employees. The former category was associated with the satisfying of transitory needs of companies, unlike the latter category of standard workers (Camas, 2013). Secondly, the increased mobility of temporary workers on the labor market - on the one hand, as a result of frequent employment of this class of workers on short-term temporary contracts, usually no longer than 3 months, and on the other hand, as a result of employers' resorting to fixed-term contracts as a favored means for dealing with transitory needs, without any interest in turning these workers into steady employees - greatly contributed to the lack of skilled labor force occurring in Spain (Camas, 2013) ${ }^{17}$, with a significant impact especially on the young population.

\section{c) Regarding the lower pay than permanent employees' remuneration}

This category of workers also has a special position generated by the economic effects of fixed-term contracts, from the standpoint of employees. Numerous surveys have demonstrated that, although law consecrates the principle of payment parity for fixed-term workers and permanent workers, respectively, actually the former category earns less than the employees holding permanent, steady positions. Specialized juridical literature (Alvarado, 2014) has shown, for instance, that in Spain there is a $12 \%$ difference in pay scale, between the remunerations of fixedterm workers and permanent workers. This gap widens if we consider other characteristics of the employees in the two categories we compare: the average difference in hourly wages amounts to $15 \%$ between the fixed-term employees and their counterparts with similar tasks, but holding permanent jobs.

Similarly, the UK report such pay differentials in the case of the two groups of workers - temporary/permanent - which encompasses the gender differences. Thus, male workers employed on fixed-term contracts have an hourly income that is $16 \%$ smaller than the income of their male counterparts, who hold a permanent employment contract, while the women with fixed-term contracts earn $13 \%$ less than their male counterparts holding permanent employment contracts (Alvarado, $2014)^{18}$. Clearly, this ,penalty” imposed on fixed-term workers' salaries impacts their pension and social welfare rights, and also affects their ability to obtain bank loans (Dimitriu, 2016) or even start a family. As shown in the previous subchapter, a great asymmetry between the spheres of temporary and standard workers, respectively, also includes the access of the former category to the professional development and training programs. Therefore, a key element in maintaining this 
discrepancy in the remuneration levels, lies in the unequal skills of these two categories of employees, which has polarized the fixed-term workers in the underpaid sectors of economy. Under these circumstances, we think it useful for states to seek to adopt regulations that might reduce these vulnerabilities challenging temporary employees, in order to prevent abuse in exercising the fixedterm employment contracts.

Regarding the social welfare measures, the situation is again not in the favor of temporary employees. Eligibility criteria for social welfare payments are more complex in the case of fixed-term workers, than in the case of permanent-contract workers. Usually, the social security systems envisage the „standard employees”, and affiliation to the systems of social protection and security is a criterion linked to the standard individual employment contract (Kothe \& Rosendahl, 2013).

For example, in Germany, the unemployment insurance system provides unemployment benefits (social welfare payments) on condition that there is a waiting period of at least 12 months, and the beneficiaries pay the mandatory contributions to the unemployment insurance system. The unemployment benefits amount to $60-67 \%$ of the average net salary calculated for the last 52 working weeks, and the benefits can be paid for $6-18$ months, depending on the type of employment contract held previously, and the age of the unemployed person. Usually, the provision imposing a 12 months' waiting period, prevents young persons' access to this scheme, so they are provided welfare allowances granted by the state. Moreover, the unemployment insurance (compensation) system in Germany provides training programs for the unemployed, winter allowances for the workers in the constructions industry, as well as measures aimed to integrate disabled persons (Kothe \& Rosendahl, 2013).

Similarly, the temporary employees' access to the occupational pension schemes in the UK, as stipulated by the Fixed-Term Employees Regulation, obliges employers to allow their access to the occupational pension schemes to the same extent as the permanent employees. However, there can be exceptions to this rule in the case of fixed-term employment contracts covering a shorter duration than the period stipulated as a condition to gain the rights to the pension scheme (vesting period). In this situation, the employer could find an objective justification to exclude temporary workers from the pension scheme available to permanent employees, if including temporary workers entails disproportionate costs or brings no benefits to the employee. In order to strengthen the protection of temporary workers, this legal provision stipulates that if the employer fails to provide access to a pension scheme for temporary workers in compliance with the law, then the employer must offer to the temporary employee, in compensation, an increased salary, equivalent to the contribution to the pension system paid for a permanent worker (Koukiadaki, 2010). 


\section{Conclusions}

We easily find that it is hard to identify mutual advantages, from the standpoint of both parties, concerning the fixed-term employment contract. We may assert that a major criticism of this type of employment addresses the numerous disadvantages affecting temporary workers, in contrast with the many benefits enjoyed by the employer. The temporary character of this type of employment, the sense of great instability and low protection for those working on such contracts, the scarce opportunities for professional development and training, the limited rights and social benefits, all these are significant difficulties faced by this category of employees. Also, these difficulties met by fixed-term workers are as many constant challenges faced by the legislative bodies of EU member states, and reveal the need to adjust the stipulations regulating fixed-term employment contracts. They should pursue a reconcilement of interests of both parties involved in the fixed-term contract - both employers and employees. As our investigation indicates, the relevant legislation is still insufficient and more or less causes the instability of employment on fixed-term contracts (see: Germany, Spain, but especially Poland), as it fails to provide equal security to temporary and permanent employees. These flaws of legal systems actually result in the segmentation of labor market, divided between standard employees and temporary ones, respectively, and increasing the risk of unemployment for this specific category of workers (Ludera-Ruszel, 2016).

\section{References}

Alvarado, L. K. A. (2014) "The effects of fixed-term contracts on workers in Colombia", Cuadernos de Economia, 33 (63): 421-446

Babos, P. (2014) "Step or trap? Transition from fixed-term contracts in Central Eastern Europe", Post-Communist Economies, vol. 26: no. 1: 39-52

Blanpain, R., Nakakubo, H. \& Araki, T. (2010) "Regulation of Fixed-Term Employment Contracts", Bulletin of Comparative Labor Relations, book 76, Ed. Wolters Kluwer, 196 pp.

Burgoon, B. \& Dekker, F. (2010) "Flexible employment, economic insecurity and social policy preferences in Europe", Journal of European Social Policy, vol. 20, no. 2: 126-141

Camas, F.R. (2013) "Standard and non-standard work in Spain", in Buelens, J. \& Person, J. Standard work: anachronism?, Intersentia Publishing Ltd., Cambridge: $149-170$

Cutuli, G. \& Guetto, R. (2013) "Fixed-Term Contracts, Economic Conjuncture and Training Opportunities: A comparative Analysis Across European Labor Markets", European Sociological Review, vol. 29, no. 3: 616-629

Dimitriu, R. (2016) "Dreptul muncii. Anxietăți ale prezentului”, Ed. Rentrop \& Straton 
Elke J. J., Regina T. R. \& Schnabel C. (2012) "Feature: Flexible forms of employment: boon and bane", p. F115, in The Economic Journal, 122 (August): F115-F124, available online at https://www.cariereonline.ro /antreprenor/strategie/munca-temporara-romania-un-avantaj-pentruangajator-dar-si-pentru-angajat (on-line access: March $10^{\text {th }}$ 2017)

Kothe, W. \& Rosendahl, C. (2013) "Standard and non-standard work in Germany", in Buelens, J. \& Person, J., Standard work: an anachronism?, Intersentia Publishing Ltd., Cambridge: 65-92

Koukiadaki, A. (2010) "The Regulation of Fixed-Term Work in Britain" in Blanpain, R., Nakakubo, H. \& Araki, T. (eds.) Regulation of Fixed-Term Employment Contracts - A Comparative Overview, Ed. Wolters Kluwer: 23-49

Ludera-Ruszel, A. (2016) "Typical or Atypical? Reflections on the atypical forms of employment illustrated with the example of a fixed-term employment contract - a comparative study of selected European countries", Comparative Labor Law \& Policy Journal, vol. 37 (2): 407-445

Mooi-Reci, I. \& Dekker, R. (2015) "Fixed-Term Contracts: Short-term Blessings or Long-Term Scars? Empirical Findings from the Netherlands 19802000", British Journal of Industrial Relations, vol. 53:112-135

Vettori, S. (2008) "Fixed term employment contracts: the permanence of the temporary", Stellenbosch Law Review, vol. 19 (2): 189-208

${ }^{1}$ Alongside part-time employment, which is the best developed form of atypical employment on the labor markets.

${ }^{2}$ Countries with a well-established fixed-term employment tradition are also: Spain, Portugal, the Netherlands, where the percentage of workers on this type of contract amounts to approximately $25 \%$ of the total workforce employed. On the other hand, lower numbers of such contracts were concluded, for the same period, in Italy and Germany, with $14 \%$ and $13.2 \%$, respectively.

${ }^{3}$ It has been found that only $40 \%$ of the temporary employees gain a permanent position at the end of their first fixed-term contract.

${ }^{4}$ For instance, in Spain the women working on a fixed-term contract delay maternity, compared with women on a standard (permanent) employment contract. This has had a negative impact on the fertility rate for this category of employees.

5 This argument contributing to the mobility of employment has been substantiated in states such as the Netherlands, which have reported an increase in the number of workers transferred to permanent positions after a fixed-term employment period.

${ }^{6}$ Regarding the importance of fixed-term employment contracts for the increase in the general level of employment, the specialized literature has put forth another hypothesis. According to it, the lower labor costs entailed by fixed-term employment - due to the easy dismissal process - could encourage employers to create more new jobs.

${ }^{7}$ In Spain, surveys have shown that fixed-term employment has actually influenced the distribution of unemployment duration: this duration has increased for long-term unemployed persons, and has decreased for short-term unemployed persons, because the latter are preferred by employers.

${ }^{8}$ Literature terms it a „stepping stone”, that is, a step to permanent employment.

${ }^{9}$ See: https://www.cariereonline.ro/antreprenor/strategie/munca-temporara-romania-un-avantajpentru-angajator-dar-si-pentru-angajat, accessed on 10.03.2017.

${ }^{10}$ A survey conducted in the UK has revealed that for $17 \%$ of jobs based on a fixed-term employment contract, the main reason is gaining professional skills and abilities, while for $16 \%$ it is a way of 
ascertaining the productive potential of a worker, with a view to considering him/her for a permanent position

${ }^{11}$ Unfortunately, this situation reflects reality: the conclusion reached is that only $40 \%$ of employees on such positions succeeded in securing a permanent job. However, there are states with a higher percentage, such as Estonia and Slovakia, with $62.14 \%$ and $67.99 \%$, respectively, a situation accounted for by the different ways in which the labor market institutions regulate this transition. For instance, a legal system with strict rules that apply to the dismissal procedure has a negative influence on the opportunities for gaining permanent employment.

${ }^{12}$ Conclusion reached, for instance, in Germany and the UK.

${ }^{13}$ Who most of the times, cannot know whether his/her fixed-term employment contract can be renewed or, on the contrary, he/she risks becoming unemployed.

${ }^{14}$ Protection is also supported by the national legal systems, which have decreed that terminating a fixed-term employment contract is illegal if it does not have ,important reasons" or "social justification", in accordance with the „Protection Against Unfair Dismissal Act” (germ. Kündigungsschutzgesetz) - in which case the fixed-term employment contract continues to be in effect, and the employee is entitled to retrospective payment for the entire period.

15 Actually, this low attachment can be mutual or reversed - from the fixed-term employee to the employer - which can also provide low motivation for the employee to invest his specific human capital into the company. This also has a negative impact on the productivity of both company and worker.

16 The same author has identified an additional element which increases the risk of future unemployment for fixed-term workers: the stigma effects. According to this theory, what employer is mainly interested in the history of a worker's previous jobs, or the latest employment contract; these serve as "screening device" in the recruitment process. More exactly, the nature of the previous employment contract will have a positive or negative influence on the hiring. In the case of a worker who previously held a fixed-term contract, the risk of future unemployment is greater than in the case of a standard employment contract. Workers on previous fixed-term contracts can be perceived as "underskilled and less career-oriented, which makes the job less secure and increases the probability of reiterated unemployment for the future".

${ }^{17}$ In Spain in 2006, more than half of the population aged $15-64$ were unskilled (51.9\%) and less than a quarter of the labor force $(22.5 \%)$ were semi-skilled.

${ }^{18}$ We mention that job precarity entailed by work on fixed-term contracts is greater in states such as Germany or Poland, where the difference in the payment of fixed-term and permanent employees, respectively, can even reach $43 \%$ in the latter case. 